\title{
Pre-contoured reconstruction plate fabricated via three-dimensional printed bending support
}

\author{
In-Seok Song ${ }^{1}$, Jae-Jun Ryu', Young-Jun Choi ${ }^{2,3}$, Ui-Lyong Lee ${ }^{3}$ \\ ${ }^{I}$ Department of Dentistry, Korea University Anam Hospital, ${ }^{2}$ Department of Oral and Maxillofacial Surgery, Chung-Ang University \\ School of Medicine, ${ }^{3}$ Department of Oral and Maxillofacial Surgery, Dental Center, Chung-Ang University Hospital, Seoul, Korea
}

\begin{abstract}
J Korean Assoc Oral Maxillofac Surg 2021;47:233-236)
A mandibular continuity defect can be repaired using either a prosthetic device or autogenous bone. A titanium reconstruction plate can be used with a localized or vascularized flap over the defect of the mandible. Unfortunately, the plate may fail due to plate exposure, screw loosening, fracture, or infection, and will need to be removed. Plate exposure though the skin or mucosa is one of the main reasons for failure. In the present work, the authors introduced a lingually positioned reconstruction plate fabricated via three-dimensional printed bending support. This custom reconstruction plate can avoid plate re-exposure as well as reduce surgical errors and operation time.
\end{abstract}

Key words: Computer simulation, Mandibular defect, Reconstruction plate, Three-dimensional printing, Machine bending [paper submitted 2021. 1. 22 / revised 2021. 2. 22 / accepted 2021. 2. 23]

\section{Introduction}

A mandibular continuity defect can be repaired using either a prosthetic device or autogenous bone. A titanium reconstruction plate (R-plate) can be used with a localized or vascularized flap. Unfortunately, these plates often need to be removed due to plate exposure, screw loosening, fracture, or infection ${ }^{1-5}$. Failure of the plates is related to the size and location of the defect, smoking, diabetes, and pre- and postoperative radiation ${ }^{1,6-9}$. Among these factors, plate exposure through the skin occurs in $3.8 \%$ to $46 \%$ of cases $^{6-8,10,11}$. Once

\section{Young-Jun Choi \\ Department of Oral and Maxillofacial Surgery, Dental Center, Chung-Ang University Hospital, 102 Heukseok-ro, Dongjak-gu, Seoul 06973, Korea TEL: +82-2-6299-2875 \\ E-mail:oms@hanmail.com \\ ORCID: https://orcid.org/0000-0002-7058-4633}

\section{Ui-Lyong Lee}

Department of Oral and Maxillofacial Surgery, Dental Center, Chung-Ang University Hospital, 102 Heukseok-ro, Dongjak-gu, Seoul 06973, Korea TEL: +82-2-6299-2875

E-mail:davidjoy76@gmail.com

ORCID: https://orcid.org/0000-0002-0080-0169

(c) This is an open-access article distributed under the terms of the Creative Commons Attribution Non-Commercial License (http://creativecommons.org/ licenses/by-nc/4.0/), which permits unrestricted non-commercial use, distribution, and reproduction in any medium, provided the original work is properly cited. Copyright (C) 2021 The Korean Association of Oral and Maxillofacial Surgeons. All rights reserved. the plates are exposed, the plates are removed and the wound repaired with a vascularized bone flap ${ }^{11}$. However, elderly or medically compromised patients may not tolerate the long invasive surgical procedure required. There are few options for these patients except removal of the R-plates without further repair, resulting in a mandibular continuity defect.

Generally, in R-plate procedures the surgeons manually bend the readymade R-plate through a time-consuming trialand-error process. However, repetitive bending can increase the risk of fatigue fracture ${ }^{12}$. Therefore, the manual bending procedure should be cautious and minimal. Stereolithographic models can be created so that the R-plate can be manually bent around the contours of the model mandible $e^{13,14}$.

In the present study, the authors introduced a salvage technique of reconstructing continuity defects via lingual repositioning and a machine pre-contoured plate.

\section{Technical Note}

A 75-year-old female patient presented with exposure of two R-plates in the left cheek.(Fig. 1) Cone-beam computed tomography was taken while she was in the upright position. Patient data were stored in DICOM format and reconstructed into three-dimensional bone images using the Mimics program (ver. 19.0; Materialise, Leuven, Belgium). 
The left side of the mandible was modeled using Mimics software after subtraction of the previous R-plate. To minimize tension on the soft tissue, the posterior portion of the new R-plate was designed to be placed as medially as possible according to the contour of the lingual cortex. The virtual plate and holes were modeled three-dimensionally along the cortex of the mandible. Then, the upper and lower bending support was fabricated by additive manufacturing according

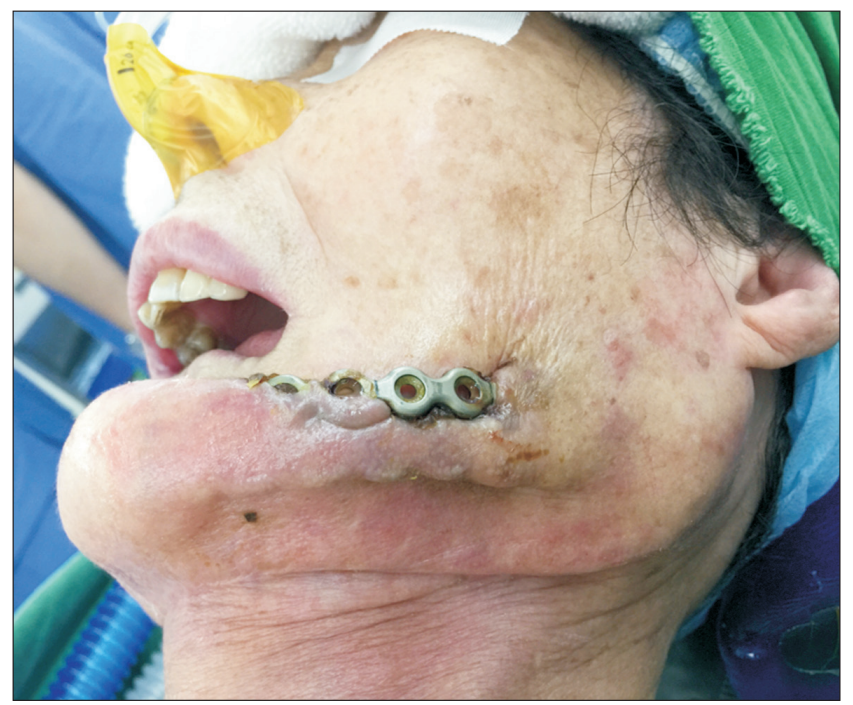

Fig. 1. Exposed reconstruction plate.

In-Seok Song et al: Pre-contoured reconstruction plate fabricated via three-dimensional printed bending support. J Korean Assoc Oral Maxillofac Surg 2021

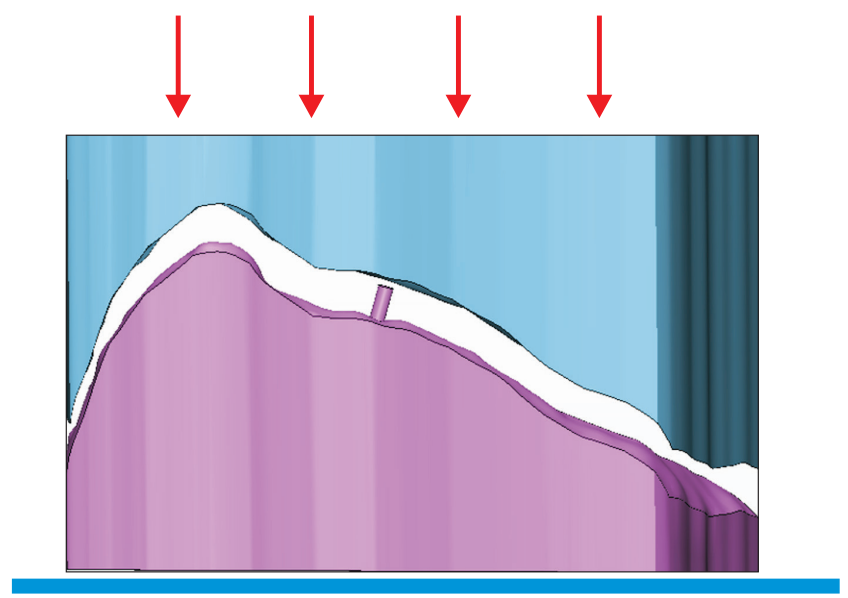

Fig. 2. Modeling of a reconstruction plate located as medially as possible according to the contours of the lingual cortex. The virtual plate and holes were three-dimensionally simulated along the cortex of the mandible. Fabrication of the lower bending support according to the mandible model. The rod on the bending support was fitted to the hole of the plate, which holds the plate during the bending procedure. Pre-contouring of the plate using a combination of upper and lower bending halves.

In-Seok Song et al: Pre-contoured reconstruction plate fabricated via three-dimensional printed bending support. J Korean Assoc Oral Maxillofac Surg 2021 to the simulated data. The lower bending support had a rod to position the straight, ready-made plate accurately.(Fig. 2) The upper bending guide was fabricated by mirroring the lower bending support. The straight commercial plate was positioned on the bending support of the press machine. The upper bending guide was anchored on the press machine, and then the pre-contoured plate was created via union of the two bending units.(Fig. 2) The edges were rounded as much as possible so that stress was not concentrated on the curved part of the titanium metal plate to minimize the possibility of plate fracture.

Clinically, a submandibular incision was made, and the skin flap was raised to remove the old plate.(Fig. 1) The old plate was removed and a pre-contoured lingual plate was inserted and fixed.(Fig. 3) The skin around the exposed plate was deepithelized and sutured again. The plate was tightly covered

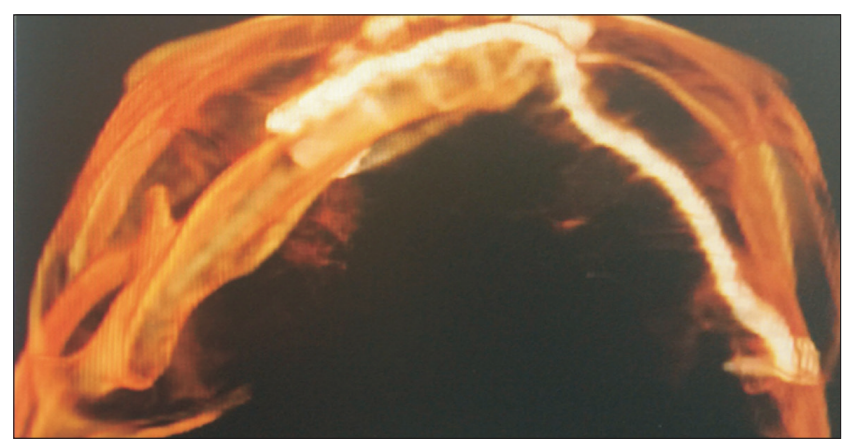

Fig. 3. Computed tomography image of the lingual pre-contoured reconstruction plate affixed to the mandibular continuity defect. In-Seok Song et al: Pre-contoured reconstruction plate fabricated via three-dimensional printed bending support. J Korean Assoc Oral Maxillofac Surg 2021

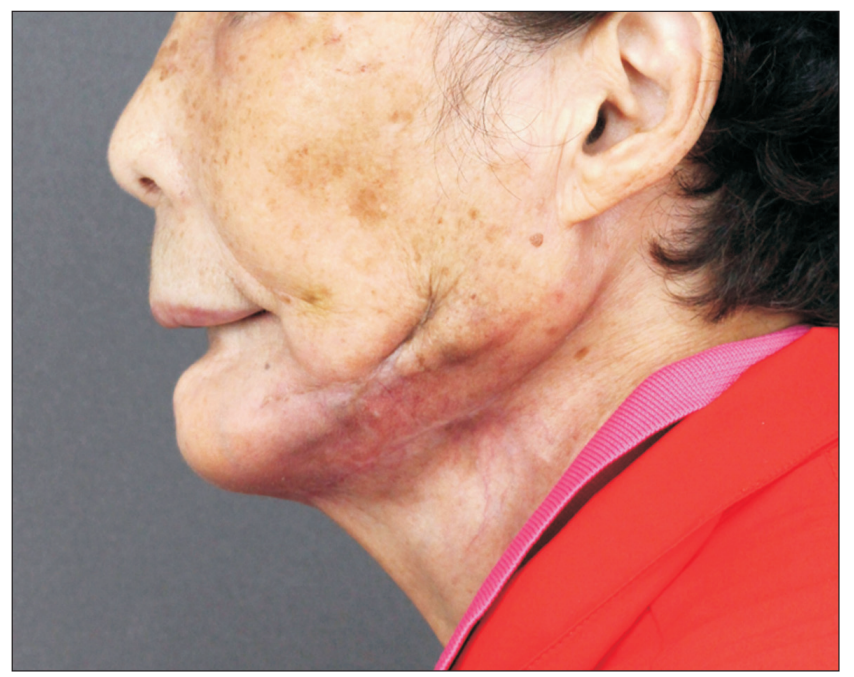

Fig. 4. Postoperative healing of the skin after 6 months. In-Seok Song et al: Pre-contoured reconstruction plate fabricated via three-dimensional printed bending support. J Korean Assoc Oral Maxillofac Surg 2021 
by the surrounding soft tissue, and the skin flap was closed. Wound healing was favorable 6 months after operation.(Fig. 4)

\section{Discussion}

This report describes a convenient and safe procedure for replacing an exposed R-plate with a new one. The previous R-plate was based on the outer surface of the mandible, and was exposed due to skin atrophy and dehiscence. A new plate contoured according to the inner surface of the reconstructed mandible limits the risk of re-exposure by preventing skin atrophy. Pre-contouring along the lingual surface of the mandible was helpful to prevent skin dehiscence and plate reexposure.

Contouring of the R-plate can be aided by manual bending based on the stereolithographic model ${ }^{14-17}$. Surgeons can estimate the defect shape and anticipate the exact contour needed for reconstruction according to a mirror image of the mandible. This simulation enables fabrication of the R-plate prior to surgery, which can dramatically reduce the operation time and yield superior outcomes ${ }^{18,19}$. The accuracy of precontoured plates was examined between the conventional plate and a plate contoured using a stereolithographic model as a reference ${ }^{13}$. The accuracy was superior in the stereolithographic group compared to conventional intraoperative plating.

Adjustive manual bending of the plate causes residual stress, which could increase the risk of fatigue fracture ${ }^{12}$. An experimental study revealed that fatigue fracture begins at the inner curvature of the plate and propagates to the outer edge due to cyclic masticatory loads; additional manual bending increases fracture risk. Therefore, the plate should closely match with mandibular outline, and require no additional manual bending ${ }^{12}$. Plates that are pre-contoured according to representative models could minimize the need for manual bending and resulting fatigue stress. In particular, the lingual bending step might be problematic and lead to plate-mandible misfit. Therefore, use of a machine pre-contoured plate wellfitted to the mandible could improve outcomes.

The authors recommend use of lingual repositioning and a machine pre-contoured plate as a safe, accurate and convenient technique for mandibular reconstruction.

\section{ORCID}

In-Seok Song, https://orcid.org/0000-0002-0763-8838

Jae-Jun Ryu, https://orcid.org/0000-0001-6903-5955
Young-Jun Choi, https://orcid.org/0000-0002-7058-4633

Ui-Lyong Lee, https://orcid.org/0000-0002-0080-0169

\section{Authors' Contributions}

I.S.S. participated in data collection and wrote the manuscript. I.S.S., J.J.R., Y.J.C., and U.L.L. participated in the study design and performed the statistical analysis. U.L.L. participated in the study design and coordination and helped to draft the manuscript. All authors read and approved the final manuscript.

\section{Acknowledgements}

This R-plate was designed by Mi-Ran Lee of Jeil Medical Corporation.

\section{Consent for Publishing Photographs}

Written informed consent was obtained from the patients for publication of this article and accompanying images.

\section{Conflict of Interest}

No potential conflict of interest relevant to this article was reported.

\section{References}

1. Spencer KR, Sizeland A, Taylor GI, Wiesenfeld D. The use of titanium mandibular reconstruction plates in patients with oral cancer. Int J Oral Maxillofac Surg 1999;28:288-90.

2. Lindqvist C, Söderholm AL, Salo A, Subasinghe J, Ylijoki S, Skutnabb K, et al. A comparative study on four screw-plate locking systems in sheep: a clinical and radiological study. Int J Oral Maxillofac Surg 2001;30:160-6. https://doi.org/10.1054/ijom.2000.0037

3. Shibahara T, Noma H, Furuya Y, Takaki R. Fracture of mandibular reconstruction plates used after tumor resection. J Oral Maxillofac Surg 2002;60:182-5. https://doi.org/10.1053/joms.2002.29817

4. Katakura A, Shibahara T, Noma H, Yoshinari M. Material analysis of AO plate fracture cases. J Oral Maxillofac Surg 2004;62:348-52. https://doi.org/10.1016/j.joms.2003.05.009

5. Schöning H, Emshoff R. Primary temporary AO plate reconstruction of the mandible. Oral Surg Oral Med Oral Pathol Oral Radiol Endod 1998;86:667-72. https://doi.org/10.1016/s10792104(98)90201-3

6. Ettl T, Driemel O, Dresp BV, Reichert TE, Reuther J, Pistner H. Feasibility of alloplastic mandibular reconstruction in patients following removal of oral squamous cell carcinoma. J Craniomaxillofac Surg 2010;38:350-4. https://doi.org/10.1016/j.jcms.2009.04.011

7. Kämmerer PW, Klein MO, Moergel M, Gemmel M, Draenert GF. Local and systemic risk factors influencing the long-term success of angular stable alloplastic reconstruction plates of the mandible. J Craniomaxillofac Surg 2014;42:e271-6. https://doi.org/10.1016/ 
j.jcms.2013.10.004

8. Liu SP, Cai ZG, Zhang J, Zhang JG, Zhang Y. [Plate related complication after mandibular reconstruction]. Zhonghua Kou Qiang Yi Xue Za Zhi 2013;48:586-90. Chinese.

9. Nicholson RE, Schuller DE, Forrest LA, Mountain RE, Ali T, Young D. Factors involved in long- and short-term mandibular plate exposure. Arch Otolaryngol Head Neck Surg 1997;123:21722. https://doi.org/10.1001/archotol.1997.01900020107016

10. Maurer P, Eckert AW, Kriwalsky MS, Schubert J. Scope and limitations of methods of mandibular reconstruction: a long-term follow-up. Br J Oral Maxillofac Surg 2010;48:100-4. https://doi. org/10.1016/j.bjoms.2009.07.005

11. Wei FC, Celik N, Yang WG, Chen IH, Chang YM, Chen HC. Complications after reconstruction by plate and soft-tissue free flap in composite mandibular defects and secondary salvage reconstruction with osteocutaneous flap. Plast Reconstr Surg 2003;112:37-42. https://doi.org/10.1097/01.PRS.0000065911.00623.BD

12. Martola M, Lindqvist C, Hänninen H, Al-Sukhun J. Fracture of titanium plates used for mandibular reconstruction following ablative tumor surgery. J Biomed Mater Res B Appl Biomater 2007;80:345-52. https://doi.org/10.1002/jbm.b.30603

13. Azuma M, Yanagawa T, Ishibashi-Kanno N, Uchida F, Ito T, Yamagata $\mathrm{K}$, et al. Mandibular reconstruction using plates prebent to fit rapid prototyping 3-dimensional printing models ameliorates contour deformity. Head Face Med 2014;10:45. https://doi. org/10.1186/1746-160X-10-45

14. Salgueiro MI, Stevens MR. Experience with the use of prebent plates for the reconstruction of mandibular defects. Craniomaxillofac Trauma Reconstr 2010;3:201-8. https://doi.org/10.1055/s-00301268520
15. Cunningham LL Jr, Madsen MJ, Peterson G. Stereolithographic modeling technology applied to tumor resection. J Oral Maxillofac Surg 2005;63:873-8. https://doi.org/10.1016/j.joms.2005.02.027

16. Coopman R, Aerden T, De Temmerman G, Politis C. Mandibular wing osteotomy: technical modification. Br J Oral Maxillofac Surg 2017;55:635-6. https://doi.org/10.1016/j.bjoms.2017.04.005

17. Chan HH, Siewerdsen JH, Vescan A, Daly MJ, Prisman E, Irish JC. $3 \mathrm{D}$ rapid prototyping for otolaryngology-head and neck surgery: applications in image-guidance, surgical simulation and patientspecific modeling. PLoS One 2015;10:e136370. https://doi. org/10.1371/journal.pone.0136370

18. Toro C, Robiony M, Costa F, Zerman N, Politi M. Feasibility of preoperative planning using anatomical facsimile models for mandibular reconstruction. Head Face Med 2007;3:5. https://doi. org/10.1186/1746-160X-3-5

19. Zweifel DF, Simon C, Hoarau R, Pasche P, Broome M. Are virtual planning and guided surgery for head and neck reconstruction economically viable? J Oral Maxillofac Surg 2015;73:170-5. https:// doi.org/10.1016/j.joms.2014.07.038

How to cite this article: Song IS, Ryu JJ, Choi YJ, Lee UL. Precontoured reconstruction plate fabricated via three-dimensional printed bending support. J Korean Assoc Oral Maxillofac Surg 2021;47:233-236. https://doi.org/10.5125/jkaoms.2021.47.3.233 